\title{
Inflammatory bowel disease and refractory anaemia (myelodysplasia)
}

\author{
R Sahay, D R Prangnell, B B Scott
}

\begin{abstract}
Two patients with colitis and refractory anaemia requiring multiple transfusions are described. In one the anaemia was detected at the onset of colitis before drug treatment; in the other it started after 21 years of treatment with sulphasalazine and during an exacerbation of colitis with perianal abscess for which he had just been started receiving prednisolone, cofluampicil and metronidazole. Glomerulonephritis developed two weeks after the onset of anaemia. These findings together with a recent report of four patients with Crohn's disease and refractory anaemia suggests that the association may be more than coincidental and may be immune mediated.

(Gut 1993; 34: 1630-1631)
\end{abstract}

Anaemia is a common finding in inflammatory bowel disease. In severe disease this is usually a normochromic anaemia of chronic disease. In some it may be hypochromic from iron deficiency as a result of blood loss, poor diet or malabsorption. In Crohn's disease it may be macrocytic from folate or B12 deficiency as a result of small bowel disease or resection. Sulphasalazine may also occasionally predispose to anaemia by folate deficiency or haemolysis. Azathioprine and mercaptopurine, which are reserved for more severe disease, may cause anaemia by marrow depression. We report on two patients with severe anaemia requiring frequent transfusion whose anaemia was refractory and whose bone marrow examination showed myelodysplasia.

Departments of

Medicine and

Haematology, County

Hospital, Lincoln

R Sahay

D R Prangnell

B B Scott

Correspondence to:

Dr B B Scott, Department of Medicine, County Hospital, Lincoln LN2 5QY.

Accepted for publication 10 March 1993

Patients' haematological data

\begin{tabular}{|c|c|c|c|c|}
\hline & \multicolumn{2}{|l|}{ Patient 1} & \multicolumn{2}{|l|}{ Patient 2} \\
\hline & August 90 & October 91 & May 92 & November 92 \\
\hline \multicolumn{5}{|l|}{ Peripheral blood } \\
\hline Leucocyte count $\times 10^{9} / 1$ & $3 \cdot 6$ & $2 \cdot 9$ & $7 \cdot 8$ & $8 \cdot 3$ \\
\hline Neutrophil count $\times 10^{\circ} / 1$ & $1 \cdot 1$ & 0.5 & $5 \cdot 6$ & 5.9 \\
\hline Haemoglobin g/dl & $8 \cdot 2$ & 8.5 & $10 \cdot 7$ & $6 \cdot 3$ \\
\hline Mean corpuscular volume $\mathrm{fl}$ & 93 & 111 & 91 & 102 \\
\hline Red cell count $\times 10^{12} / 1$ & 3.6 & $2 \cdot 1$ & 3.4 & 1.8 \\
\hline Platelet count $\times 10^{4} / 1$ & 229 & 51 & 103 & $90^{\circ}$ \\
\hline \multicolumn{5}{|l|}{ Bone marrow } \\
\hline Cellularity & Normal & Нуро & Normal & Hyper \\
\hline Trilineage dysplasia & Yes & Yes & No & Yes \\
\hline Ringed sideroblasts & None & None & None & None \\
\hline Myeloblasts \% & 9 & 16 & 9 & 4 \\
\hline
\end{tabular}

\section{Case reports}

PATIENT 1

This 71 year old white man, having been previously very well, presented in August 1990 with anaemia and slight non-bloody diarrhoea of six weeks duration. He was a former smoker. The table shows his blood count and marrow exam- ination results. His erythrocyte sedimentation rate was $146 \mathrm{~mm} / \mathrm{h}$ and the blood film showed marked rouleaux formation. Serum $B_{12}$ and folate concentrations were normal. Serum IgG was raised at $26.5 \mathrm{~g} / \mathrm{l}$ and $\operatorname{IgA}$ at $5.9 \mathrm{~g} / \mathrm{l}$. Barium enema showed narrowing and loss of haustral pattern from the mid transverse colon to the lower descending colon suggestive of Crohn's disease, colonoscopy showed petechial haemorrhages and loss of vessel pattern in the sigmoid and descending colon up to $45 \mathrm{~cm}$. The rectum and the colon above $45 \mathrm{~cm}$ were normal. Histological examination of biopsy specimens showed inflammation of variable intensity with some gland atrophy and depletion of goblet cells. A diagnosis of Crohn's colitis was made. He was given a four unit blood transfusion but the colitis was not treated at that time because the diarrhoea was not troublesome.

In March 1991 he developed pyoderma gangrenosum at the left ankle. He was treated with mesalazine in the long term and prednisolone for three months. A repeat bone marrow examination, aspirated with difficulty, in October 1991 is shown in the Table with the blood count. It was classified as refractory anaemia with excess of blast cells according to the French-AmericanBritish (FAB) classification. ${ }^{1}$ His bowels did not trouble him again. He continued to need blood transfusions of 2-4 units every 2-3 months receiving a total of 32 units over the next 20 months. In May 1992 he had a pancytopenia (haemoglobin - $7 \cdot 8 \mathrm{~g} / \mathrm{dl}$, white cell count $1 \cdot 2 \times 10^{9} / 1$, platelets $\left.-14 \times 10^{9} / 1\right)$. Despite transfusions, platelet infusions and drugs he died with fever, confusion, epistaxes, haematuria, and rectal bleeding.

\section{PATIENT 2}

This white man, a former smoker, whose brother had had a colectomy for colitis, was admitted in September 1991 at the age of 66 with an exacerbation of colitis first diagnosed in 1969 and a perianal abscess. He had had periodic treatment with sulphasalazine and local steroids. His haemoglobin was $14.0 \mathrm{~g} / \mathrm{dl}$ with a leucocyte count of $13 \cdot 1 \times 10^{9} / 1$, and a platelet count of $106 \times 10^{9} / 1$. Sigmoidoscopy showed diffuse inflammation with petechial haemorrhages up to $45 \mathrm{~cm}$ and from $45-60 \mathrm{~cm}$ the mucosa was polypoid. A rectal biopsy specimen showed inflamed mucosa with acute cryptitis. Colonic biopsy specimens showed more severe inflammation with crypt abscesses. No granulomata were seen. He responded to a one month course of prednisolone, sulphasalazine, and drainage of pus from the abscess.

From 29 September to 9 October 1991 he was given oral metronidazole and from 28 September 
to 1 October he was given cofluampicil. On 1 October he developed a severe erythematous rash and oedema of his legs attributed to cofluampicil. Also on 1 October his haemoglobin had fallen to $11 \cdot 1 \mathrm{~g} / \mathrm{dl}$ and to $5 \cdot 6 \mathrm{~g} / 1$ by 4 November. His previously normal urea and creatinine rose to 20 $\mathrm{mmol} / \mathrm{l}$ and $386 \mu \mathrm{mol} / \mathrm{l}$ respectively. They remained at that concentration for a month before improving to a creatinine of $230 \mu \mathrm{mol} / \mathrm{l}$ and a normal urea. They have remained at that concentration since. A renal biopsy showed a fairly acute immune complex mediated glomerulonephritis, chronic ischaemia/ hypertensive type damage, and tubular damage possibly related to recent sepsis. Serum C3 complement was reduced at $0.33 \mathrm{~g} / 1$; 4 complement was normal. The Table shows the result of a bone marrow examination. The appearance was of myelodysplasia or refractory anaemia in the FAB classification. Chromosomal analysis was normal. He was treated with repeated blood transfusion requiring 31 units over the next 12 months (2-6 units every two months). The colitis has remained in remission on sulphasalazine. A repeat blood count and bone marrow examination in November 1992 is shown in the Table.

\section{Discussion}

Both these patients had chronic inflammatory bowel disease. Patient 1 almost certainly had Crohn's colitis because of the rectal sparing although the histology was not diagnostic. Patient 2 was thought to have ulcerative colitis on the basis of typical sigmoidoscopic findings and histology. The development of a perianal abscess, however, and the slightly less severe disease in the rectum raises the possibility of Crohn's colitis. Histological tests of neither bowel or inflamed perianal skin showed granulomata. They both also suffered from severe myelodysplasia. Myelodysplasia is a heterogeneous bone marrow clonal stem-cell disorder characterised by peripheral cytopenia and marrow dysplasia.

Crohn's disease probably has an incidence approaching 5 per 100000 per year. ${ }^{2}$ Twelve cases of myelodysplasia are diagnosed per year in north Lincolnshire giving an incidence of six per 100000 per year. Four patients with both Crohn's colitis and myelodysplasia were reported by Eng and colleagues ${ }^{3}$ in 1992 and so the association may be more than coincidental. In three of those patients the anaemia came before the colitis making a drug cause unlikely. They speculate on the possible link invoking an impairment of immune function. The raised serum IgG and IgA concentrations in patient 1 and the almost synchromous development of immune complex glomerulonephritis in patient 2 would lend some support to an immune mechanism, as would the report of cutaneous vasculitis in patients with myelodysplasia. ${ }^{4}$ The occurrence of both the anaemia and the glomerulonephritis as well as the rash straight after treatment with metronidazole and cofluampicil raises the possibility of drug induced disease in that patient.

We suspect that as a result of these reports more cases will be recognised and a clearer picture may emerge of the relation of inflammatory bowel disease (especially Crohn's colitis) and myelodysplasia. There is no satisfactory treatment of the haematological problem. At present most patients are supported with repeated transfusion of blood and platelets, and antibiotic treatment is given promptly for infections. The discovery of an underlying immune disturbance might open the way to a new therapeutic avenue.

1 Bennett JM, Catovsky D, Daniel MT, Llandrin G, Galton DA, Gralnick HR, et al. Proposals for the classification of the myelodysplastic syndromes. Br F Haematol 1982; 51: 189-99. 2 Mayberry JF, Rhodes J. Epidemiological aspects of Crohn's disease: a review of the literature. Gut 1984; 25: 886-99.

3 Eng C, Farraye FA, Shulman LM, Peppercorn MA, Krauss CM, Connors JM, et al. Ann Intern Med 1992; 117: 661-2. CM, Connors JM, et al. Ann Intern Med 1992; 117: 661-2. 4 Green AR, Shuttleworth D, Bowen DT, Bentley DP. Cutaneous vasculitis in patients with myelodysplasia. $\mathrm{Br} \mathcal{f}$
Haematol 1990; 74: 364-70. 